\title{
COMMENT ON WHITE ON THE RELATIONSHIP BETWEEN ECONOMICS AND ETHICS
}

\author{
JoHn B. Davis *
}

\begin{abstract}
- ABSTRACT
This short comment on Mark White's comment on the relationship of economics and ethics focuses on the nature of economics and ethics as an emergent field of investigation. It discusses different types of between-discipline fields, and compares crossdisciplinary and transdisciplinary interpretations of economics and ethics. The 'domestication' thesis associated with borrowing across disciplines is examined in terms of the idea of a metaphorical transfers. Institutional constraints on between-discipline developments are evaluated relative to increasing specialization within and across disciplines. The transdisciplinary interpretation of economics and ethics is given a complexity theory explanation.
\end{abstract}

Keywords: Crossdisciplinary, Transdisciplinary, Trolley Problem, Domestication, Specialization, Complexity.

JEL codes: A12, B41.

\section{Introduction: Investigating EMERgENT Disciplinary FieldS}

Mark White's examination of economics and ethics as a field of investigation makes the relationship between different disciplines central to its explanation and understanding as an emergent disciplinary field. Drawing on Jordi Cat's discussion of the different ways in which different disciplines can be related (Cat, 2017), he characterizes economics and ethics as a crossdisciplinary field in which economics and ethics each borrow from one another to serve their independent disciplinary goals (White, 2018). This implies that potentially there are two economics and ethics fields, one

* Marquette University and University of Amsterdam. Address for correspondence: john. davis@marquette.edu. 
within economics and one within philosophy with relatively little communication between them. White focuses on economics and ethics as a crossdisciplinary field within economics, and then argues that the field itself has had two, opposite forms of development. One, carried out largely by heterodox economists, is essentially a critical discourse that examines what is regarded as a mis-use and distortion of concepts and theories borrowed from ethics in their introduction into economics. The other, carried out mostly by orthodox or mainstream economists, he labels 'accommodationist' to capture their goal of adapting concepts and theories from ethics to the goals of explanation in economics.

White's analysis provides a model of explanation for reflection upon emergent, between-discipline fields of investigation that are the product of different existing fields and are located within one or both of their contributing fields. In the case of new fields within economics that result from borrowings from other disciplines, other current examples are behavioral economics, neuroeconomics, econophysics, ecological economics, and bioeconomics. Each of these new fields might also be argued to also have two identities in a manner similar to economics and ethics, so to fully appreciate their nature we should look for and compare their elaboration in both of their contributing fields.

We can contrast this form of emergent field development with what Cat terms transdisciplinarity, where a new field develops in a free-standing way outside of existing fields which jointly contribute to it. ${ }^{1}$ In social science, network theory, matching theory, systems theory, and complexity theory might be examples, while in natural and physical science, bioengineering and bioastronautics are examples. In this case, that a new field stands outside of existing fields suggests its development is unconstrained, or at least relatively less constrained, by its contributing fields, and as a consequence may be less easy to explain. The crossdisciplinary case, in contrast, seems conceptually to be a more straightforward sort of one to investigate, because within the disciplines where they are being developed the imprint of the contributing disciplines plays a relatively clear role in the emergent field's definition. White's two forms of development analysis of economics' economics and ethics, with heterodox and orthodox forms, then, helps create an agenda for doing so.

In particular, his treatment of these two forms as heterodox and orthodox tells us that there is likely little communication between them, so that there exists a tension in the development of the field. Thus, the heterodox

1 White compares crossdisciplinarity with multidisciplinarity rather than transdisciplinarity. I address the difference below. 
approach completely rejects the accommodationist project while the latter seems to ignore the former, such that it is odd to say they both constitute approaches within the same discipline. Only the institutional fact that contributors to the two approaches are trained in and publish in in the same discipline (if in quite different outlets) makes them contributors to the same inquiry. This schizophrenia might constitute a barrier to the field's development, since it leaves unresolved fundamental questions about its basis. But it might also be the case that this sort of tension is productive of the field's development. To see this, consider the famous Trolley dilemma that White discusses.

\section{The Trolley Dilemma as a Test Case}

The Trolley dilemma was developed in ethics as a thought experiment by philosophers to test people's intuitions about whether utilitarianism and an emphasis on the greatest good or deontological, duty-based ethical principles take greater precedence in people's reasoning. ${ }^{2}$ That is, faced with the dilemma, where in order to save a number of people one has to intentionally sacrifice a single person, one can make a choice about what to do that rests on either utilitarian or deontological ethical grounds, but not on both. One set of principles has to be sacrificed for the other. As White explains, then, proponents of an accommodationist economics and ethics are more likely to adopt a utilitarian solution, and heterodox critics are likely to argue that this unacceptably violates our sense of duty central to deontological reasoning, and demonstrates orthodox economics' inability to absorb ethical reasoning.

Accommodationists' commitment to the utilitarian view, of course, reflects economics' long-standing utilitarian orientation. Though cardinal utility theory, which had explicit greatest good meaning, has been replaced by ordinal utility theory which abandons the greatest good idea, the latter's Pareto efficiency reasoning is still essentially utilitarian. The Pareto criterion, which recommends states of affairs that make at least one person better off without worsening the circumstances of others, simply produces greatest good improvements in a marginalist manner one person at a time way. White emphasizes the connection between this framework and economists' characterization of individual motivation as being essentially self-interested. Not only, then, is the standard economics framework utilitarian, but the idea that individual behavior is self-interested is directly

\footnotetext{
2 See White's references.
} 
in conflict with deontological ethics which sets duties above self-interest. Thus, the standard approach promotes one type of ethical thinking and demotes another. If dilemmas require hard choices and do not allow choices that address all concerns, then critics argue standard economics has simply made its choice.

At the same time, White points toward how the standard treatment of choice in economics as currently being developed within the mainstream might be enlarged to accommodate duties. Duties can be formally modelled as a special type of constraint on self-interest maximization, much like a legal constraint. This will not satisfy proponents of the strongest theory of duties, the Kantian one, in which observing duty requires one act out of a moral motive, not just act in accordance with an ostensible duty. But there are other theories of duty, and economic modelers could reply that this is how they believe self-interest and duty are reconciled. People observe duties because they think they ought to, but may have other grounds for doing this, so it seems duty can be accommodated in the standard economics approach. ${ }^{3}$

My point here, however, is not to defend or evaluate the adequacy of orthodox economics' treatment of ethics. Rather it is to explain how on the crossdisciplinary view an emergent field such as economics and ethics might develop within one discipline, here economics. Thus, on White's accommodationist pathway, that development inevitably presupposes a discipline's existing framework. ${ }^{4}$ Disciplines, in effect, configure their borrowed, other-discipline contents according to the requirements of their own internal conceptual structures. This tells us again how much more difficult explaining a transdisciplinary field that is developed outside existing disciplines can be, since the role of inherited structures there is less clear. But my focus is rather on a specific question raised by the accommodationist pathway: how does the adoption of borrowed, other-discipline contents affecting the borrowing field?

\section{The 'Domestication’ Thesis}

By this expression I refer to how borrowed, other-discipline contents are transformed when introduced into a borrowing field. The term 'do-

3 A similar argument can be made about how a virtue ethic might be accommodated in the standard choice framework if behaving virtuously is interpreted as observing certain constraining rules of behavior one sets for oneself in maximizing one's self-interest.

4 The same could be said about how an economics and ethics might develop within the discipline of philosophy (rather perhaps, ethics and economics). 
mestication' is used metaphorically in order to liken the effect of this borrowing to how people domesticate animals, such as a family pet. At the same time, the idea of metaphor performs an analytical role, since it refers to a process whereby an accepted meaning and usage in one conceptual space is transferred to another, preserving some of its original meaning but also taking on new meaning in its new context (cf. Hills, 2016). In principle this process can have different outcomes, which we might place along a continuum. At one extreme, the adopted expression ultimately loses most of its original meaning, and has its meaning transformed to fully reflect its new location. It is fully or largely domesticated. At the other extreme, the adopted expression still does not retain all of its original meaning, but retains enough of it to alter the conceptual space into which it is inserted. In effect, the inheriting framework experiences a 'domestication' of sorts as well. At this extreme, moreover, there is the additional issue of the degree to which this alteration occurs.

As an example of the first extreme, consider Adam Smith's popularization of the idea that free markets work as if guided by 'an invisible hand.' The original meaning of the expression is of something being guided by a force behind the scenes or out of view - perhaps a theological image. However, Smith's meaning in using the expression is that free markets work without governmental organization and independently of any managing authority. Today, more than two centuries after Smith's intervention in economics discourse, the expression is largely coincident with its economic meaning. It remains a metaphor, and is still used outside of economics, but its original connotation plays little role in its understanding, and the economic meaning has become the most familiar. When people refer to the 'invisible hand' idea they are using a compact expression to explain how they believe markets operate.

As an example of the second extreme, consider the more recent economics concept of game theory. Game theory in economics refers to the analysis of strategic bargaining where people's choices are interdependent. The idea was borrowed from a long human history of games played in the home by family members and guests, where its meaning reflected a non-market interaction in which the stakes involved were insignificant and games were merely a source of entertainment (cf. Leonard, 2010). This idea no longer applies to game theory in economics, since strategic interaction occurs in public market settings, and much can be at stake. At the same time economics has been transformed by its development of game theory. For Smith, competitive markets work at arm's length (another metaphor!) and the identity of market participants is irrelevant to their interaction. In game theory, interdependence makes who one interacts with central to outcomes, and thus changes what economics has historically been seen to 
be about. In this case, then, the borrowing process has had transformative effects on the borrowing discipline.

Let us return to the issue of crossdisciplinary development of emergent fields. The 'domestication' idea allows for both the heterodox view of economics and ethics as a mis-use and distortion of ethics ideas in their development in economics and also for the possibility that economics' borrowing from ethics might genuinely absorb ideas from ethics into economics. I suggested above, then, that the co-existence of these two, opposite approaches in economics' economics and ethics potentially might create a tension affecting the field's development. How might that happen?

That there seems to be relatively little communication between the two approaches suggests that it is not their contact with one another that matters. That is, the heterodox critique does not seem to have had direct effects on the accommodationist program. Yet, the thrust of the heterodox critique is likely nonetheless known to accommodationists. Orthodox economists are not unfamiliar with the charge that economics' standard account of choice behavior does not include - perhaps excludes - a treatment of moral motives. Likely many orthodox economists are not inclined to say moral motives never intrude on economic behavior - especially since the development of the behavioral economics argument that non-rational motives often influence choice.

So it seems reasonable to say that the heterodox critique has had indirect effects on the accommodationist program, and that the tension between the approaches has accordingly had an impact on economics' economics and ethics field. Moreover, it can be argued that the domestication process this involves falls toward the latter extreme on the continuum above (the game theory example), where the borrowing of other discipline concepts influences economics itself - a sort of 'domestication' of economics itself.

White, then, emphasizes the self-interest motive as the underlying cause of maximization behavior. He recognizes "altruistic and more broadly ethical behavior can be modeled with the ordinary techniques of economic theory ... tweaking standard conceptions of preferences and utility to generate maximizing behavior that incorporates the well-being of others". I agree. Indeed, as economics has moved away from narrative-based explanations to formal modelling, it has opened the door to multiple interpretations of its formalisms. Formally, maximizing behavior is explained as acting on one's own preferences (where a utility function is subscripted as belonging to some individual), but the content of those preferences need not be self-interested and can be other-regarding in many ways. One can have preferences regarding the well-being of others, regarding social causes, etc. Presumably the movement of economics to formal modeling as its principle form of explanation is independent of the development of 
its field of economics and ethics. But that change might facilitate not only the borrowings the field carries out but also influence the degree to which this borrowing affects the nature of economics as a discipline.

Heterodox critics of the accommodationist program will likely not be persuaded that this will bring about an adequate economics and ethics. Their standards for this are quite strong in the sense that they might require the abandonment of not only the maximization framework but also much else in economics associated with economics' historic attachment to the fact-value distinction. Whatever the merits are of this view, it is unrealistic as a strategy for the crossdisciplinary development for economics' economics and ethics, where the internal structure of economics cannot be set aside. In the next section, however, I position this concern relative to a transdisciplinary rather than crossdisciplinary approach to economics and ethics, and map out a view of economics and ethics rival to economics' economics and ethics.

My intention in the discussion above, then, was not to settle the dispute between heterodox and accommodationist approaches within economics' economics and ethics, but to map out how on the crossdisciplinary view we might think about the evolution of economics and ethics within economics. Borrowing contents from other disciplines can affect the borrowing discipline, and can, in principle, have important effects on the borrowing discipline. This is not an insignificant conclusion. In the following two sections, however, I turn to how economics and ethics could develop as a field beyond its current crossdisciplinary development within economics.

\section{A Transdisciplinary Approach to Economics and Ethics?}

White regards multidisciplinarity as an alternative to crossdisciplinarity, but I propose we consider how economics and ethics might become a transdisciplinary approach. A multidisciplinary approach preserves and combines the many of the main elements of its contributing disciplines. That is, "it involves the juxtaposition of the treatments and aims of the different disciplines involved in addressing a common problem" (Cat, 2017, sect. 3.3). In contrast, a transdisciplinary approach produces a new hybrid field that develops in a free-standing way outside of the fields which contribute to it that presumably bears less of the imprint of its contributing disciplines. That is, a transdisciplinary approach results in "a synthetic creation that encompasses work from different disciplines" (Ibid.).

White's focus on multidisciplinarity makes sense should we think of multidisciplinarity as a logical first step in an emergent field's development beyond crossdisciplinarity. Yet if an emergent field outside of its contribut- 
ing disciplines is to develop as a fully autonomous field of investigation, it seems it ought to ultimately develop as a transdisciplinary field. This, of course, may not occur, particularly in the institutional research environment that currently exists, in which researchers are trained and employed mostly within different disciplines. Let me outline in the balance of this section, however, how such a development might occur. In the section following this one, I will interpret this transdisciplinary vision of economics and ethics specifically as a complexity theory approach. ${ }^{5}$

If a key barrier, then, to transdisciplinarity is the institutional separation of researchers' training and professionalization, we need to identify forces operating contrary to this to explain how economics and ethics might develop as a transdisciplinary field. I focus on one such force: specialization in research. As is well known, specialization as long been a significant force explaining economic development. Thus, if we see research activity as one kind of production, we should expect specialization to play an important role there as well. Consider, then, Ronald Heiner in this regard (1983).

Heiner examines the incentives facing researchers in their professional development. On the one hand, their personal advancement depends on making new contributions. On the other hand, the sheer growth of knowledge in all disciplines over time creates what he calls a 'competence-difficulty gap' whereby they are more and more uncertain about how to effectively allocate their scarce research time. This suggests that they are likely to increasingly specialize in their research, focus on new, uninvestigated topics, and become expert on those highly specialized topics. One possible consequence of this behavior is that disciplines may become increasingly fragmented because researchers' efforts go entirely into specialization and no one has an incentive to synthesize the increasing disciplinary fragmentation this involves. A further possible consequence, specifically relevant to the issue of disciplinarity, is that the boundaries of disciplines may become less clear because there is decreasing understanding of what disciplines as a whole involve (cf. Davis, 2018).

Transdisciplinarity develops when the influences of contributing disciplines become less clear in an emergent free-standing discipline. Assuming that the forces of specialization operate across research, then over time we would expect there to be more transdisciplinary research should researchers find themselves investigating shared topics outside their disciplines. That is, their attachment to shared topics of research may exceed their attachment to their disciplinary origins. This leaves unanswered, however,

5 See Schinkus and Jovanovic (2013) for an argument that econophysics is a transdisciplinary approach that draws on complexity theory thinking. 
why different types of highly specialized research with originally different disciplinary origins might turn out to overlap in shared topics of research outside of those disciplinary origins. To address this issue, the following section advances a complexity theory vision of economics and ethics as a transdisciplinary field.

\section{A Complexity Theory Vision of Economics and Ethics}

There are many versions of complexity theory, but Herbert Simon's (1962) influential statement of what complexity involves is especially useful. His main intuition about complex systems is that they are made up of multiple, relatively independent subsystems whose interaction: (i) influences both their own activities but also the performance of the whole complex system which together they make up, (ii) involves changes which in turn reverberate back upon how these subsystems interact, (iii) so that the interacting subsystems and the whole system constantly influence each other in a continuing dynamic of change. That is, he supposes that interaction of relatively independent subsystems determines both the nature of complex systems as single entities and how their structures change over time. In effect, bottom-up and top-down influences interact to produce change on both levels.

Thus, in the case here, the contributions of economics and ethics as disciplines constitute relatively independent subsystems operating within an emergent transdisciplinary economics and ethics. Yet their interaction arguably influences not only this field as a whole but also these relatively independent subsystems themselves, transforming their contributions beyond their original nature. Whether this process in the case of economics and ethics occurs as Simon outlines depends on whether it generates a shared topic of investigation to which researchers gravitate. I argue it could for the following reason.

Both economics and ethics investigate social valuation systems, in economics, economic values, and in ethics, moral values. They differ in the rules they understand to be involved, but nonetheless both see valuation as rule-based and thus an object of systematic analysis. Economics and ethics as a field of investigation by nature concerns the interaction of these two types of valuation. For example, there is the argument that there some things that should not be an object of price valuation, such as human life (Sandel, 2012). Others note that things once thought not subject to market valuation have come to be priced in markets (Roth, 2007). One thing this suggest is that debates over the interaction of economic and moral value is 
a changing terrain. Arguments regarding the priority of either can be challenged when we examine specific cases and circumstances according to our intuitions about them. Thus, in a complex way, the interaction of these two types of thinking imposes limitations on each other, and neither should be expected to make an unchanging contribution to their synthesis.

This possibility of course does not assure us that economics and ethics will develop as a transdisciplinary field. One reason to still be skeptical about this is that the institutional constraints on research activity noted above remain largely in place. In particular, as White reminds us at the beginning of his Comment, there are few research outlets independent of traditional disciplinary locations for economics and ethics. Working against this is the tremendous expansion of non-traditional forms of publication through working paper sites and new forums in internet communication. But it remains to be seen what the ultimate impact of this might be in the future on not just economics and ethics but other multi- or transdisciplinary forms of investigation.

\section{Concluding Comment}

Mark White's "Comment on the relationship between economics and ethics" makes the issue of how disciplines interact central to both their own development and development of domains that fall between them. If the emergence of such domains increases the potential for further development of other new domains, by continually expanding the base on which between-discipline development occurs, then it is conceivable that relationships between different disciplines will come to occupy a larger space in the development of future thinking than will occur within well-defined, established disciplines. This would make investigating the different forms of between-discipline development increasingly important. The framework used here that distinguishes different form of such development invites us to begin to explore the possible pathways this might involve. Economics and ethics offers an excellent point of entry in this regard in that it brings together two established disciplines of investigation which may share more than initially appears to be the case.

\section{REFERENCES}

Cat J. 2017, “The Unity of Science”, in E.N. Zalta (ed.), The Stanford Encyclopedia of Philosophy. Available at: https:/ / plato.stanford.edu/archives/fall2017/entries/scientific-unity/ (accessed September 12, 2018). 
Cedrini M. and Fontana M. 2018, "Just Another Niche in the Wall? How Specialization Is Changing the Face of Mainstream Economics", Cambridge Journal of Economics, 42 (2): 427-451.

Davis J. 2019, "Ethics and Economics: A Complex Systems Approach", in M. White (ed.), Oxford Handbook of Ethics and Economics, Oxford: Oxford University Press.

- (2018) "Specialization, Fragmentation, and Pluralism in Economics", Working Paper.

Heiner R. 1983, “The Origin of Predictable Behavior”, American Economic Review, 73 (4): 560-595.

Hills D. 2016, "Metaphor", in E.N. Zalta (ed.), The Stanford Encyclopedia of Philosophy. Available at: https://plato.stanford.edu/archives/fall2017/entries/metaphor/ (accessed September 13, 2018).

Leonard R. 2010, Von Neumann, Morgenstern and the Creation of Game Theory, Cambridge: Cambridge University Press.

Rотн A.E. 2007, "Repugnance as a Constraint on Markets", Journal of Economic Perspectives, 21 (3): 37-58.

Sandel M. 2012, What Money Can't Buy: The Moral Limits of Markets, New York: Farrar, Straus and Giroux.

Schinckus C. and Jovanovic F. 2013, “Towards a Transdisciplinary Econophysics", Journal of Economic Methodology, 20 (2): 164-183.

Simon H. 1962, "The Architecture of Complexity", Proceedings of the American Philosophical Society, 106 (6): 467-482.

White M. 2018, "On the Relationship between Economics and Ethics", Annals of the Fondazione Luigi Einaudi, 52 (1): 47-57. 